\title{
Finite element crash simulations of the human body: Passive and active muscle modelling
}

\author{
S MUKHERJEE $^{1}$, A CHAWLA $^{1}$, B KARTHIKEYAN $^{1}$ and A SONI ${ }^{1}$ \\ ${ }^{1}$ Department of Mechanical Engineering, Indian Institute of Technology Delhi, \\ New Delhi 110016 \\ e-mail: sudipto@mech.iitd.ernet.in
}

\begin{abstract}
Conventional dummy based testing procedures suffer from known limitations. This report addresses issues in finite element human body models in evaluating pedestrian and occupant crash safety measures. A review of material properties of soft tissues and characterization methods show a scarcity of material properties for characterizing soft tissues in dynamic loading. Experiments imparting impacts to tissues and subsequent inverse finite element mapping to extract material properties are described. The effect of muscle activation due to voluntary and non-voluntary reflexes on injuries has been investigated through finite element modelling.
\end{abstract}

Keywords. Passive and active muscle modelling; human body; finite element model.

\section{Introduction}

In the process of designing vehicles that are safer, the first step is to identify the components of the vehicle that cause injury and their zone of action on the human body. For example, in a car-to-pedestrian collision, the bumper of the car causes the injuries to lower leg and knee joint of the pedestrian. This has been studied using standardized, instrumented, anthropometrical mechanical models of human bodies, crash dummies. The second step is to understand the injury mechanism in the segment of the human body under impact. Biomechanical models such as human volunteers, human cadavers, animals and mechanical human surrogates are widely used to generate experimental corridors. Volunteer experiments, for obvious ethical reasons, cannot be performed in the higher injury severity range. Crash dummies are designed to reproduce predefined load deformation corridors in specific loading directions. Their use is effective in analysing situations where the loading sequence is known, as in car riders who are strapped in. Pedestrian impact configurations are more uncertain in terms of pre-crash orientation and posture and it has not been possible to design a bio-fidelic pedestrian dummy till date. For understanding injury mechanisms, a better understanding of the effects caused by mechanical impacts to the body are needed.

Computer simulations have become an important tool in analysing biomechanical response and understanding injury mechanisms. At present, the widely used simulation techniques are multi body system (MBS) approach (Happee et al 1998), and the finite element (FE) 
method (Iwamoto et al 2002). The simplest models are lumped mass models, where a system is represented by one or more mass elements often connected by mass-less springs and dampers. These are effective drawing-board tools in design when good estimates of the model parameters are available. In contrast, a multi body system comprising of geometric bodies connected by the kinematic joints allows computation of make and break of contact forces and their magnitudes in a more general manner. The input to such systems is load versus deformation characteristics, which are used in conjunction with geometrically computed penetration to arrive at contact forces. This technique has proved its strength in simulating whole body kinematics during impact loading but cannot predict point data like stresses or strains. MADYMO ${ }^{\mathrm{TM}}$ (TNO 2001) is one of the most frequently used software for multi body simulations. The FE technique uses a discretized definition of the geometry and the constitutive laws relating stresses and strains as inputs. Thus it can predict stresses, strains, and the deformed shapes of bodies at the cost of significantly greater computational effort. An appropriate choice of the technique has to be made based on the problem being addressed.

Recently it has become computationally feasible to use detailed material models incorporating rate dependent properties in conjunction with explicit time integration algorithms such as in PAM-CRASH ${ }^{\mathrm{TM}}$. Human body finite element models such as Human Model for Safety (HUMOS1 and HUMOS2) developed through European projects (Arnoux et al 2001), and the total Human body Model for Safety (THUMS) (AM50, height $175 \mathrm{~cm}$, weight $77 \mathrm{~kg}$ ) by the Toyota Central Research and Development Lab (Iwamoto et al 2002) have been assembled. The bio-fidelity of these models relies on an anatomically accurate and detailed representation of human body segmental geometry and material characterization of the tissues. The geometry has been generated to sufficient accuracy through CT and MRI scans. There is a significant gap in the availability of material models and parameter characterization of tissues, especially under dynamic loading. In this report, the focus has been on modelling of lower extremities relevant to pedestrian-vehicle crashes as it is a special need for Indian conditions.

Muscles when treated as soft tissues act as passive members, modifying the impact between the bone and the external surface. As active members, they modify loads at the joint, relieving ligament loading, and hence limiting injury. Experiments to characterize impact loading of muscle tissues and methodology to estimate the passive loading characteristics have been presented. Secondly, the effect due to muscle activation on ligament loading in lower body impacts loading the knee in shear and bending is investigated through FE modelling.

\section{An overview of available human tissue properties}

\subsection{Hard tissue}

Bones and other calcified parts of the body are classified as hard tissues. Yamada (1970) and few others (Iwamoto et al 2000, Untaroiu et al 2005, Evans 1973) report properties of dry as well as wet bones from different body regions when subjected to static and dynamic loading conditions. The experimental procedures for testing limbs with or without soft tissues in three or four point bending are well established (Kerrigan et al 2003, Iwamoto et al 2000). Today the success in mimicking the human body behavior in impact is limited by the accuracy of soft tissue modelling.

\subsection{Soft tissue}

Soft tissues in the human body include skin, skeletal muscles, tendons, ligaments, blood vessels, fat, and cartilage. Internal organs like kidney, lungs, liver, brain tissue, etc. are labelled 
as very soft tissues. Effective modelling of soft tissues has been limited by the complexity of their biomechanical properties as they exhibit non-linear, inelastic, heterogeneous, anisotropic characteristics (Humphrey 2002).

A two-step process is usually employed to characterize soft tissue material property: (i) identification or development of a constitutive model for the soft tissue; (ii) extraction of parameters in the material model that matches experimental data.

There are several numerical-experimental techniques available to extract soft tissue material properties corresponding to the material model (Miller-Young et al 2002, Miller \& Chinzei 1997, Weiss et al 2002, Untaroiu et al 2005). However, till date, there is little data on the response of soft tissues to impact. One reason for this may be that FE techniques and computational means to utilize this data has evolved only recently.

\subsection{Ligaments}

Ligaments are dense connective tissues that are connected to multiple bones, maintaining skeletal alignment while allowing articulation of the joint (Viano 1986). Viscoelasticity and rate dependency of the ligament tissues have been widely reported (De Vita \& Slaughter 2005, Bonifasi-Lista et al 2005, Amis et al 2003, Hingorani et al 2004, Gardiner 2002, Pioletti et al 1999, Crisco et al 2002, Funk et al 2000, Yamamoto et al 2003). The effect of thawing (Azuma 2003), freezing (Woo \& Orlando 1986, Moon et al 2005), specimen holders (Sharkey et al 1995, Lepetit et al 2004), and characterizing material models (Weiss 1994, Weiss et al 2002, Gardiner 2002, Pioletti 1997, Pioletti et al 1998, Pioletti \& Rakotomanana 2000, Provenzano 2002, De Vita \& Slaughter 2005) has been reported. Most of the ligament properties reported were characterized for applications in surgical simulations (Hingorani et al 2004, Fleming \& Beynnon 2004) and are at very slow strain rates compared with crash simulations. Recent studies on knee ligaments for modelling pedestrian finite models indicate that not only high-speed response but anisotropy may also be an issue (Untaroiu et al 2005, Limbert \& Middleton 2005, Song et al 2004).

\subsection{Tendon}

Tendons are formed with thick band of collagen fascicles that connect skeletal muscle directly to bone and transmit tensile forces during muscle contraction, tending to actuate the joint (Viano 1986). Mechanical properties of tendon are determined using tensile testing (Maganaris 2002). The effect of strain rate on tendon response (Sverdlik \& Lanir 2002, Ng et al 2004, Robinson et al 2004, Lynch et al 2003, Wren et al 2001), size (Boyer et al 2001, Liao \& Vesely 2003), specimen holder (Wieloch et al 2004) and pre-conditioning (Sverdlik \& Lanir 2002) are available in the literature on the subject. Yin \& Elliott (2004) proposed biphasic transversely isotropic constitutive model to characterize the tendon response in tensile loading.

\subsection{Skeletal muscle}

Skeletal muscles can be modelled with passive properties when muscle activation is not an issue. Muscles then act as padding, modifying the impact between the bone and the external surface. Modelling with active muscle properties depending upon posture has been shown to modify the kinematics post impact. Passive response is dominated by the structures associated with the muscle's connective tissue and its fibres (Van Eijden et al 2002). In finite element simulations, passive muscles are usually modelled as three-dimensional, structural, solid 
elements. Active muscles are usually represented using one-dimensional elements accounting only for the force in the axial direction. In this paper an attempt is made to modal forcelength and force-velocity relationships for activation of muscle, varying with the posture and stimulation level.

\section{Passive muscle modelling}

\subsection{Available properties}

The initial work on the material property extraction of passive muscles dates back to the 1960's (Yamada 1970). The lack of accurate muscle properties for validating the human finite element model under impact loadings is widely acknowledged (Iwamoto et al 2003, Mukherjee et al 2003, Untaroiu et al 2005, Van Sligtenhorst et al 2005). McElhaney (1966) conducted in vitro tests on bovine muscle for dynamic loadings at strain rates of up to 1000/s in which the muscle was loaded parallel to the fibre orientation. During pedestrian impact, the load is usually applied transverse to the fibre direction and is primarily compressive. Viscoelastic response of live skeletal muscles under tensile loading (Best et al 1994, Myres et al 1998) at lower strain rates (less than 100/s) is available. Bosboom et al (2001) measured the mechanical properties of rat skeletal muscle under in vivo compression transverse to the fiber direction. Dhaliwal et al (2002) compared the compressive response of volunteers, cadaveric specimens and Hybrid III dummies for low energy impact. The study reveals that the response of cadavers and relaxed volunteers are found to be similar at low energy impacts but stiffer than Hybrid III force deformation corridor. Individual muscle forces were not isolated and extension of their method on volunteers for higher strain rates is unfeasible for obvious ethical concerns.

Compressive properties of the human muscle for applications in pedestrian impact modelling have not been reported in the literature. The strain rate dependency of compressive properties on individual lower extremity muscles is not well established, especially at higher strain rates. Hence, new test methodologies supporting the strain rates above 100/s are required to understand the muscle response under impact loads.

\subsection{Material models}

Constitutive relations mathematically relate the deformation of a material to applied loads, which of course depends on the internal constitution of the material. The mathematical models in use to represent the behavior of the passive skeletal muscle are: (i) hyperelastic material model, (ii) visco-elastic material model.

Materials undergoing large reversible deformations are called hyperelastic material and its stress-strain relationship is represented using strain energy functions. Strain energy density is the area under the stress vs stretch curve, which is the energy required to deform a material per unit volume. Hyperelastic formulations provide a framework for numerical modelling of soft tissue structures by allowing large deformations on incompressible and non-linear material. The commonly used hyper elastic material models to predict the soft tissue responses are Mooney Rivilin models (Miller \& Chinzei 1997, Miller-Young et al 2002) and Ogden models (Bosboom et al 2001). An extension of the Ogden model considering the viscoelastic behaviour is reported in Basboom et al (2001). This model is not suitable when the loading and unloading do not follow the same path, demonstrating hysteresis; or in capturing the influence of strain rate on mechanical properties (Weiss et al 1996).

The viscoelastic model accounts for strain rate dependency and also captures the hysteresis effect. The commercial human body FE models available today model soft tissue as 
viscoelastic (Iwamoto et al 2003, Lizee et al 1998, Bandak et al 2001) though linear viscoelastic models do not capture the behaviour at strains above $50 \%$.

\subsection{Inverse finite element material characterization methods}

Testing with quasi-static compression loading (Miller \& Chinzei 1997, Miller-Young et al 2002), ramp tests (Bosboom et al 2001), aspiration experiments (Kauer et al 2002) and indentation tests (Durand-Reville et al 2004, Delalleau et al 2005, Erdemir et al 2005) have been used to characterize the soft tissues at strain rates less than 100/s using inverse numerical characterization techniques. Non-linear optimization algorithms like the Levenberg-Marquardt method, (Kauer et al 2002, Moulton \& Creswell 1995, Quapp \& Weiss 1998, Erdemir et al 2005) are commonly used. These gradient-based optimization methods involve computing derivatives of the constitutive equations during stress calculations are however unwieldy for complex material models.

To overcome the shortcomings in gradient-based optimization methods, an inverse FE characterization method using 'design of experiments' approach has been developed for extracting the material properties of muscle tissue at strain rates ranging from 136/s to 262/s (Karthikeyan et al 2006). A methodology to characterize the impact behaviour of passive muscle tissues has been reported.

3.3a Impact test set-up: The details of the experimental set-up, shown in figure 1, to test the muscle tissue under impact loading and, specimen preparation have been reported in Karthikeyan et al (2005). Goat tissues were tested for strain rates ranging from 131/s to $647 / \mathrm{s}$ to calibrate the set-up and evaluate a formulation for property extraction. Subsequently, uniaxial compressive-impact loading tests on human tissues have been conducted at strain rates ranging from $136 / \mathrm{s}$ to $262 / \mathrm{s}$.

The tests were designed to model unconfined conditions, that is, the specimens were allowed to expand freely in the lateral direction. Since the friction coefficient between the specimen and the constraining surfaces is not known accurately, an increase in the number of contacting surfaces increases the uncertainties in the experiment. Unconfined tests were designed in this study so as to minimize the number of contact surfaces.

3.3b Finite element simulations: A finite element model representing the experimental conditions was developed to mimic the impact test. A finite element mesh of the top platen and tissue was generated in the I-DEAS software (UGS-PLM solutions, USA) using eight-node solid elements (figure 2) and analysis performed using PAM-CRASH ${ }^{T M}$ (ESI group, France). Soft tissue was modelled using a linear viscoelastic material model:

$$
G(t)=G_{0}+\left(G_{0}-G_{1}\right) e^{-\beta \tau}
$$

Initial guess for the material properties (Lizee et al 1998) and definition of the terms in equation 1 are shown in table 1.

3.3c Parameter estimation: Taguchi methods were used to compare the experimental and the predicted finite element stress at 50\% strain and minimizing the error between them for an optimal fit. Optimal fit between experiment and finite element stress-strain response is obtained by the following steps:

(i) Selection of constitutive law, which is capable of predicting the stress-strain response of soft tissue. (ii) Identification of sensitivity of the individual material parameters. (iii) Selection of number of levels/settings for each material parameter. (iv) Selection of Orthogonal 

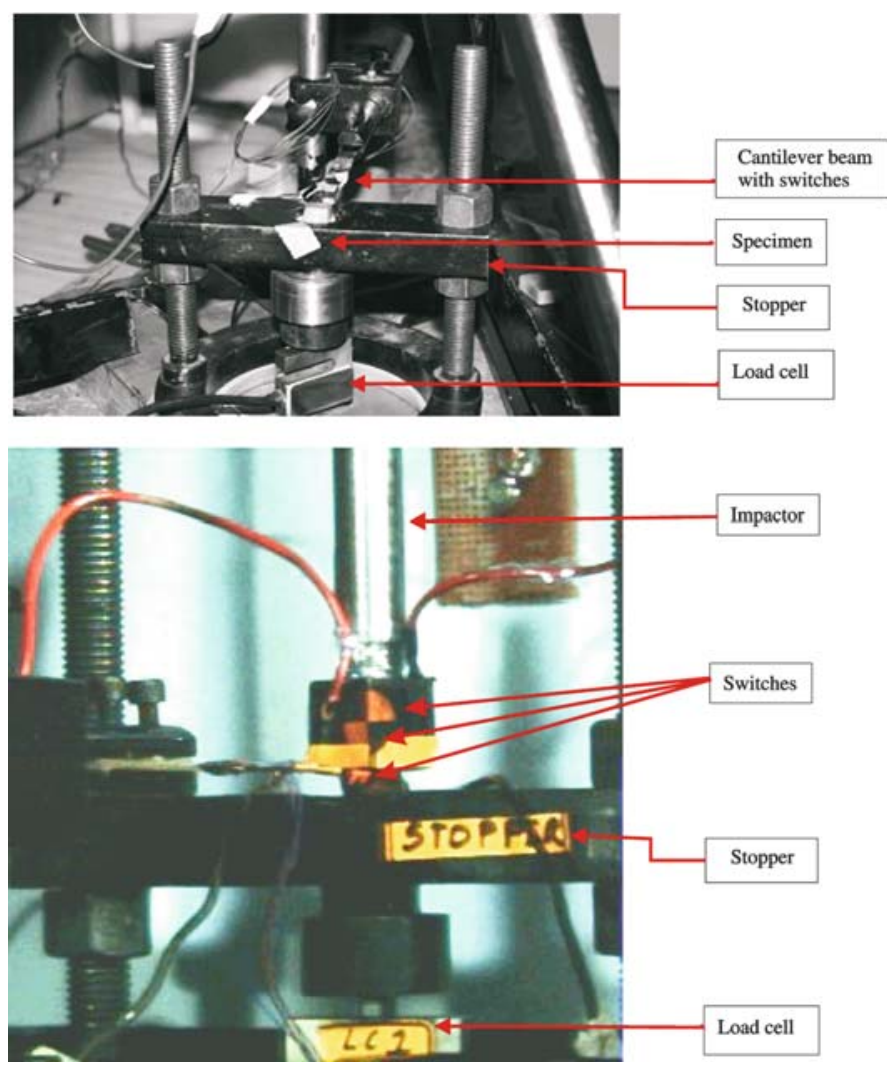

Figure 1. Impact test set-up.

Array (OA) and assigning material parameters in the matrix. (v) Conducting simulations and recording the response as per the OA matrix. (vi) Calculation of main factor effects and predicting the maximum response settings for next iteration until the optimal fit is reached.

The response variable used to conduct this study is maximum stress (Dar et al 2002). The algorithm for material property optimisation based on Taguchi Methods is shown as a flow chart of the process in figure 3. An optimal fit between finite element and experiment response

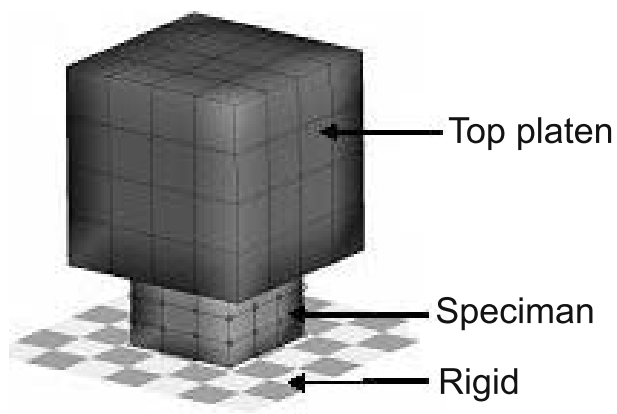

Figure 2. Finite element model of soft tissue and the top platen and rigid wall. 
Table 1. Initial material properties of soft tissue and top platen.

\begin{tabular}{ccccc}
\hline \multicolumn{5}{c}{ Soft tissue represented as linear visco-elastic material } \\
\hline $\begin{array}{c}\text { Bulk modulus } \\
(\mathrm{K})\end{array}$ & $\begin{array}{c}\text { Short-term shear } \\
\text { modulus }\left(G_{0}\right) \\
\mathrm{Pa}\end{array}$ & $\begin{array}{c}\text { Long-term shear } \\
\text { modulus }\left(G_{1}\right)\end{array}$ & $\begin{array}{c}\text { Decay constant } \\
(\beta)\end{array}$ & $\begin{array}{c}\text { Density } \\
(\rho) \\
\mathrm{Pa} / \mathrm{m}^{3}\end{array}$ \\
\hline 250000 & 115000 & 86000 & 100 & 1000 \\
\hline
\end{tabular}

at the above mentioned strain rates are presented in figure 4. Initial estimates of the short-term shear modulus and long term shear modulus obtained from Lizee et al (1998) were found to be two and six times less than the identified optimal values at 262/s. The bulk modulus obtained by the impact test and the initial estimate are similar. Strain rate dependency is indicated because of the observed deviation in the optimal properties for different strain rates. The linear visco-elastic model may not be sufficient to model this phenomenon.

\section{Active muscle modelling}

\subsection{Muscle mechanics}

The amount of force generated by a muscle depends upon muscle parameters such as pennation angle, physiological cross section area, optimum muscle fibre length, maximum muscle contraction velocity, and level of muscle activation. In human muscles, fibres are arranged in fusiform (parallel fibre arrangement), unipennate, bipennate or multipennate arrangement. Arrangement of muscle fibres, called the muscle architecture, decides the functional behaviour of a muscle. For example, parallel fibre arrangement favours range of motion whereas pennate arrangement favours greater force development (Van 1998). Pennation angle accounts for this behaviour and is defined as the angle at which muscle fibre bundles are aligned to a tendon running along the long axis of a muscle. To account for angle of muscle fibres in

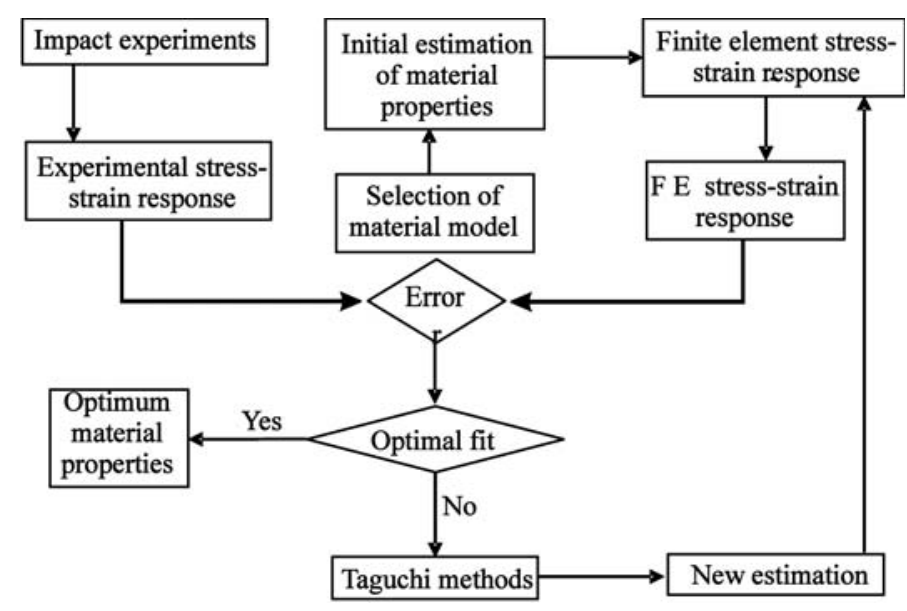

Figure 3. Schematic diagram of parameter estimation procedure. 


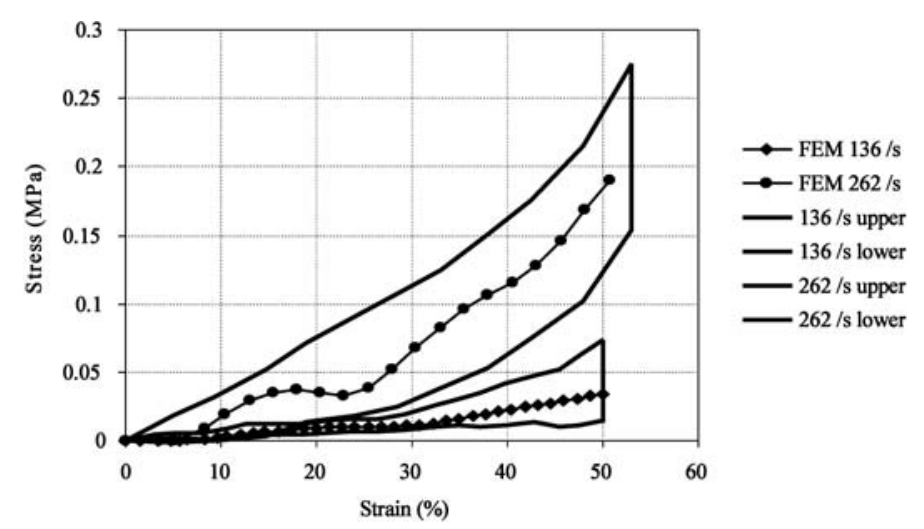

Figure 4. Comparison of finite element stress-strain response with identified properties of soft tissue against experimental corridors.

calculation of active muscle force, cross sectional area transverse to muscle fibre direction, known as the physiological cross sectional area, is used. It is also a measure of maximum active muscle force, which describes the strength of a muscle.

\subsection{Hill muscle model}

A three component mechanical model representing active and passive behaviour of a muscle, proposed by Hill (1938), is still the most commonly used model. It describes the force response of an activated skeletal muscle in terms of deformation and the rate of deformation of the entire muscle. This model consists of a contractile element (CE) to account for the active forces generated by a muscle and a visco-elastic element to account for the passive forces in a muscle as shown in figure 5. The visco-elastic component consists of a non-linear spring (PE) and a linear damper (DE). A variety of modifications to this basic model of muscles have evolved later (Crowe 1970, Gottlieb \& Agarwal 1971) to describe the behaviour of an activated muscle.

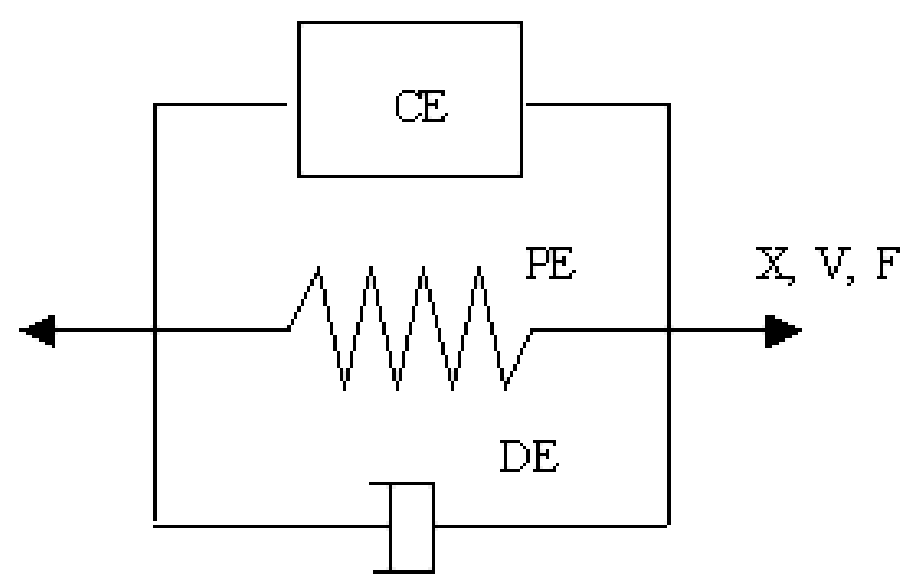

Figure 5. Hill type muscle model. 
The total force generated by a muscle fibre is the sum of the forces generated by all three components i.e.,

$$
F_{\text {Total }}=F_{C E}+F_{P E}+F_{D E}
$$

where

$$
\begin{aligned}
F_{\text {Total }} & =\text { Total muscle force } \\
F_{C E} & =\text { Force of contractile element } \\
F_{P E} & =\text { Force of parallel spring element } \\
F_{D E} & =\text { Force of dashpot element }
\end{aligned}
$$

The force response of the contractile component is a function of an instantaneous value of the active muscle state, $N a(t)$ an instantaneous muscle length $\mathrm{L}$, and its instantaneous elongation/contraction rate $\mathrm{V}$ :

$$
F_{C E}(x, v, t)=N a(t)^{*} F_{l}(x)^{*} F_{v}(v),
$$

where

$N a(t)$ represents the amount of muscle activation.

$F_{l}(x)$ represents the force-vength characteristics function.

$F_{v}(v)$ represents the force-velocity characteristics function.

The active muscle state $N a(t)$ is interpreted as the ratio of a current value of muscle force to the maximal muscle force that can be exerted by a muscle at a given length and elongation/shortening rate.

$$
N a(t)=\frac{F_{\text {current }}}{F_{\max }}
$$

Thus $N a(t)$ is a dimensionless quantity ranging from its minimum possible value of 0.005 to a maximum of 1 . It was found that in vivo conditions, resting muscles has an activation of 0.005, Winters \& Stark (1988).

Length of a muscle also affects the ability of the muscle to generate tension. Force-length characteristics $\left(F_{l}\right)$ of a muscle are used to characterise this behaviour. The first experiments on isolated frog muscles to demonstrate a relationship between length and the tension generated when contracting was conducted as early as 1894 . Later, Close (1972), studied the dynamic behaviour of mammalian skeletal muscles and demonstrated the importance of the rest length of a muscle. The rest length of a muscle is defined as the length at which the tension in an inactive muscle is zero. Thus the optimum length of a muscle is defined as the length at which maximum isometric titanic tension may be developed by a muscle. It has been found that it lies in between $100 \%$ and $120 \%$ of the rest length (Mow et al 1993). A relationship given by Audu (1985) can be used to describe the force-length characteristics of an activated muscle.

$$
F_{l}(x)=F_{\max } \exp \left[-\left(\frac{\frac{l}{l_{\text {opt }}}-1}{C_{s h}}\right)^{2}\right]
$$

Where $C_{s h}$ defines shape parameter that determines the concavity of the muscle force-length characteristics. For most muscles, Winters \& Stark (1988) have estimated the value of $C_{s h}$ to be between $0 \cdot 3$ and $0 \cdot 5$. 
The active force-velocity relationship $F_{v}$ shows that the capacity of an activated muscle to generate force decreases with its shortening. This relationship is divided into shortening and lengthening parts. When the muscle is forced to lengthen, the force reaches the plateau. Hill (1938) was the first to describe a hyperbolic relationship in isotonic force generated by a skeletal muscle and its contraction velocity. Subsequently Audu (1985), Winters \& Stark (1988), Winters (1990) and De Jager (1996) have evolved a set of normalized equations to describe force-velocity characteristics.

$$
F_{v}\left(V_{n}\right)= \begin{cases}0 & \text { for } V_{n} \leq-1 \\ \frac{C_{\text {short }}\left(1+V_{n}\right)}{C_{\text {short }}-V_{n}} & \text { for }-1<V_{n} \leq 0 \\ \frac{C_{\text {leng }}+C_{m v l} V_{n}}{C_{\text {leng }}+V_{n}} & \text { for } V_{n}>0\end{cases}
$$

Where $V_{n}$ is the muscle elongation/shortening rate normalized to the maximum shortening velocity $V_{\max }$, i.e. $V_{n}=\frac{V}{V_{\max }}$. The Hill-type shape parameter for muscle shortening, $C_{\text {short }}$, is between 0.1 and 1 . The shape parameter for muscle lengthening $C_{\text {leng }}$, is between 0.07 and $0 \cdot 17$; and $C_{m v l}$ determines the ration of ultimate force during active lengthening to isometric force at full activation is of the order of 1.3 to 1.5 .

Brolin et al (2005) have used the Hill muscle model to implement neck muscles in finite element model of human cervical spine to study neck response in car crashes and reported that muscle activation reduces the risk of injury to spinal ligaments.

\subsection{Effects of muscle active force on pedestrian knee joint}

A FE model of the human knee developed by the Honda group was validated against some of the experimental results reported by Kerrigan et al (2003), Takahashi et al (2002). The knee model in the Total Human body Model for Safety (THUMS) developed by the Toyota Central Research and Development Lab has been validated against various experimental test conditions by Nagasaka et al (2003). FE models of the knee have been used in various studies (Schuster et al 2000, Maeno \& Hasegawa 2001, Takahashi et al 2002, Matsui 2001, Nagasaka et al 2003, Chawla et al 2004) to investigate knee injury mechanism and criteria.

In the real world, car-pedestrian accidents occur in varied pedestrian postures. Muscle forces at joints maintain the posture and are expected to affect post-crash kinematics and stresses. It has been reported that the effective stiffness of joint increases with an increase in level of muscle activation and the number of recruited muscles. Louie et al (1984) have reported an increase in knee joint stiffness over $400 \%$ due to lower extremity muscle contraction in internal-external knee joint rotations and have explained that muscle contractions are crucial in protecting the knee joint structures in rapid loading conditions such as skiing. Pope et al (1979) showed that the reaction time for self-generated muscle forces $(220 \mathrm{~ms})$ is probably too long for voluntary forces to protect the joint in most cases of rapid loading. However, musculature contracted for posture control or for other motion function could play a role in protecting the structures at the knee joint.

To verify the hypothesis that contracted muscles protect the knee joint during rapid loading, in Soni et al (2006) we had reported preliminary results on the effects of inclusion of preimpact active muscle forces on knee loading for a standing pedestrian. The lower extremity of the THUMS model was used as the base FE model (Chawla et al 2004) and validated against experimental data reported by Kajzer et al (1999).

Forty muscles from 8 muscle groups as per Glitsch \& Baumann 1997) were modelled as bar elements with the Hill material model. Simulations have been conducted with and without 

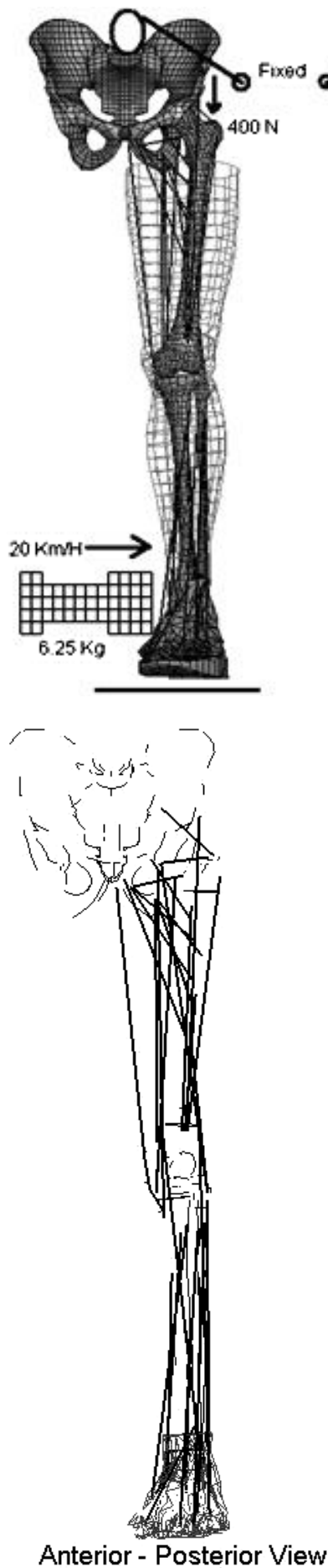
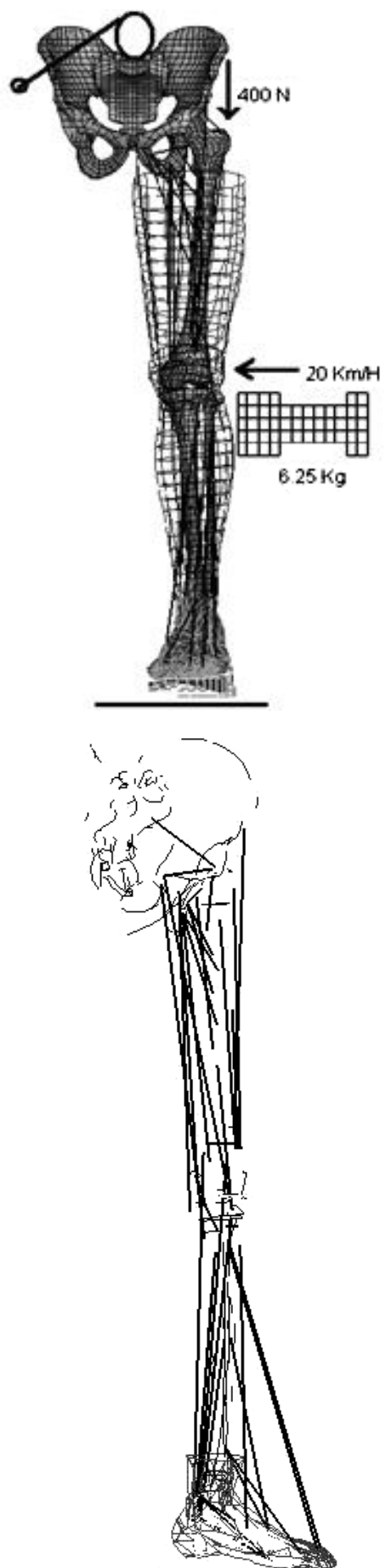

Medial - Lateral view
Figure 6. Finite element model of lower extremity (a) Simulation set-up for ankle impact (left) and below knee impact (right) in anterior-posterior view. (b) Anterior-posterior and mediallateral views showing 40 lower extremity muscles with adequate activation levels defined in the Hill type muscle bar elements to maintain an upright standing posture (Soni et al 2006). 


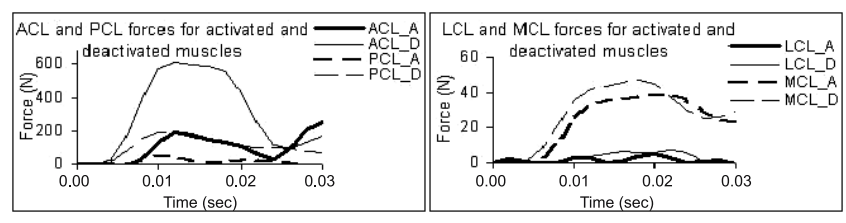

Figure 7. Comparison of forces in knee ligaments for the standing posture with below-knee impact. The A curves are curves with activated muscles and the D curves are those with deactivated muscles (Soni et al 2006).

muscles for the impact situations reported by Kajzer et al $(1997,1999)$ called the below knee and ankle impact loads here. Figure 6 shows the simulation set-up used for the below knee and ankle impacts. It is assumed that the pedestrian was unaware of the eminent crash. Therefore, only muscle forces required to maintain the standing human posture in a quasi static mode at the pre-impact stage were included. Reflexive actions to account for involuntary contraction in muscles during the impact event were incorporated in the simulations through the Hill model. Stretch reflex option was activated to allow muscles to respond to overstretching.

In order to interpret the results, forces in the knee ligaments are used to assess the probability of injuries in knee ligaments for both below knee and ankle impact loading. Figure 7 compares the forces in ligaments in below knee impacts with activated and deactivated muscle models. In below knee impact loading, maximum force of $180 \mathrm{~N}$ in ACL (Anterior Cruciate Ligament), $60 \mathrm{~N}$ in PCL (Posterior Cruciate Ligament) and $80 \mathrm{~N}$ in MCL (Medial Collateral Ligament) are predicted with activated muscles. It is observed that peak forces in ligaments are significantly lower when the muscle effects are taken into account.

Figure 8 compares the forces in ligaments in ankle impact with activated and deactivated muscles. It is observed that force build-up in LCL (Lateral Collateral Ligament) relatively lower which is not unexpected as the ankle is impacted from the inner side, limiting the LCL stretch. Significantly, lower peak values of ligament forces, $50 \%$ reduction in the ACL and reduction to very small values for the MCL, PCL and LCL are observed when muscle effects are taken into account. Figure 9 shows the muscle forces in this simulation, which are substantial. These results reinforce the hypothesis that muscle forces protect the joint structure in rapid loading conditions.

The variation of the impact force with the bending angle for below knee impact and ankle impact is shown in figure 10. The knee bending angle is larger in simulations with activated muscles for both the loading cases. This is because in the simulations, the location of the instantaneous centre of rotation (ICR) of the knee joint changes along with the change in direction of muscle forces (figure 11). This changes the moment arms of the muscles with respect to the effective point of knee rotation and the torque produced by the active muscle forces increases. This eventually increases the knee bending angle in simulations with the activated muscles.

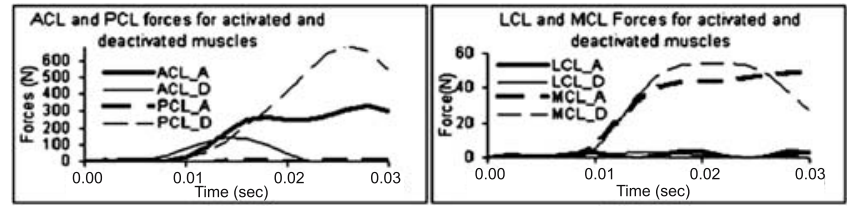

Figure 8. Comparison of forces in knee ligaments for the standing posture with ankle impact loading. The A curves are curves with activated muscles and the D curves are those with deactivated muscles (Soni et al 2006). 


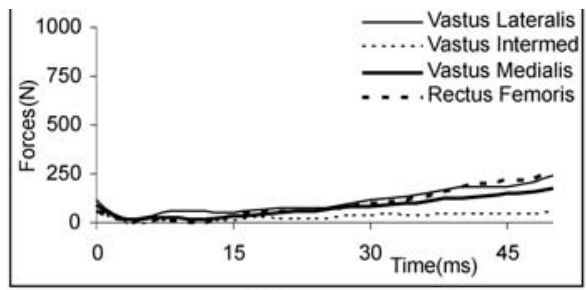

(a)

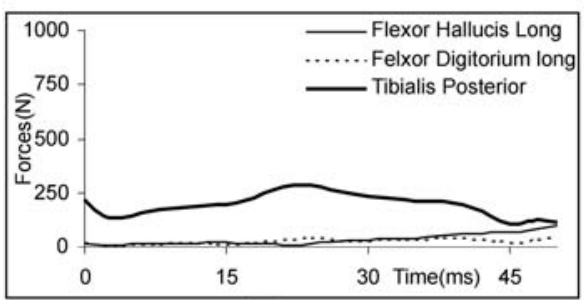

(c)

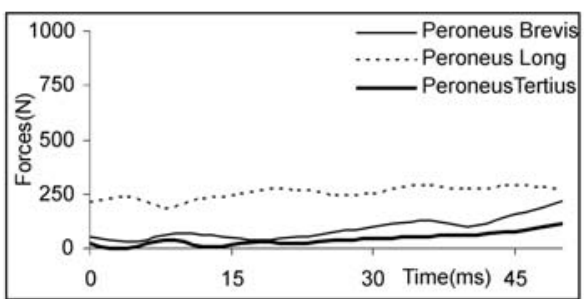

(e)

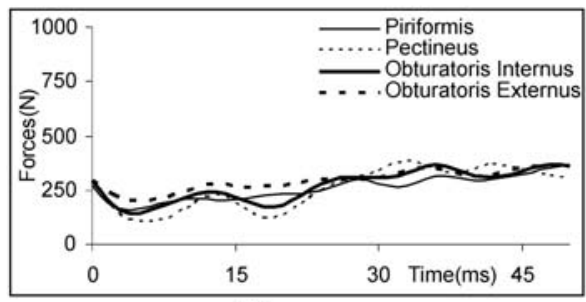

(g)

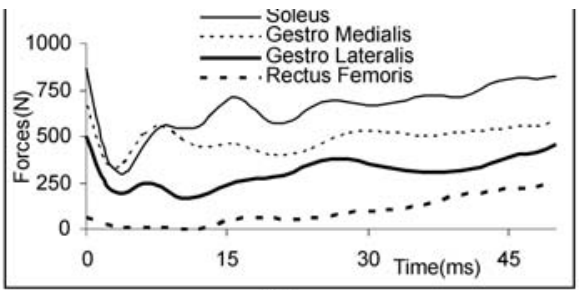

(b)

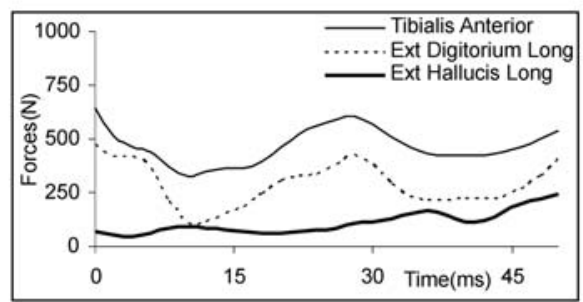

(d)

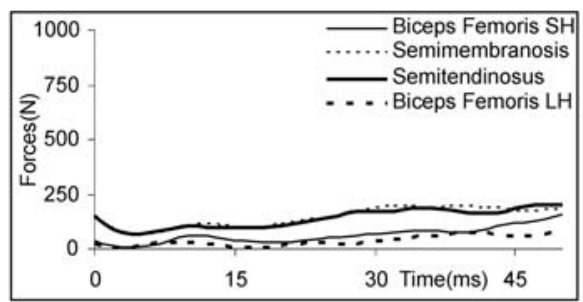

(f)

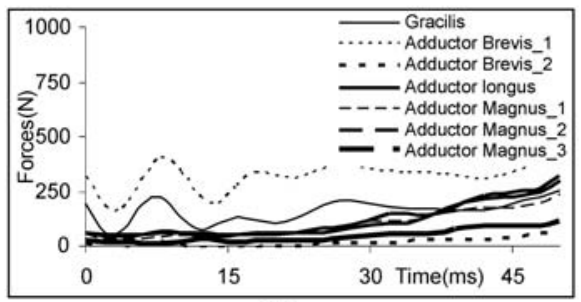

(h)

Figure 9. Variation in the muscle forces for the simulation with ankle impact loading. 40 Muscles are modelled in 8 groups (a) quadriceps, (b) triceps surae, (c) plantar flexors, (d) dorsi flexors, (e) fibularis, (f) hamstrings, (g) hip muscles, (h) hip adductors.

The impact force - shear displacement response for below knee impact and ankle impact is shown in figure 12. The responses for the activated muscles are compared with that for deactivated muscles. It indicates that the shear displacement remains smaller for the simulation with the activated muscles. Other effects of muscle activation and its implication in terms of bone fracture are currently being further investigated.

It can be seen that in low velocity lateral impacts, activation in lower extremity muscles reduces the forces in knee ligaments by a factor of 2 or more. Thus, we can conclude that activation of muscles would protect the knee ligaments in these lateral impacts. 

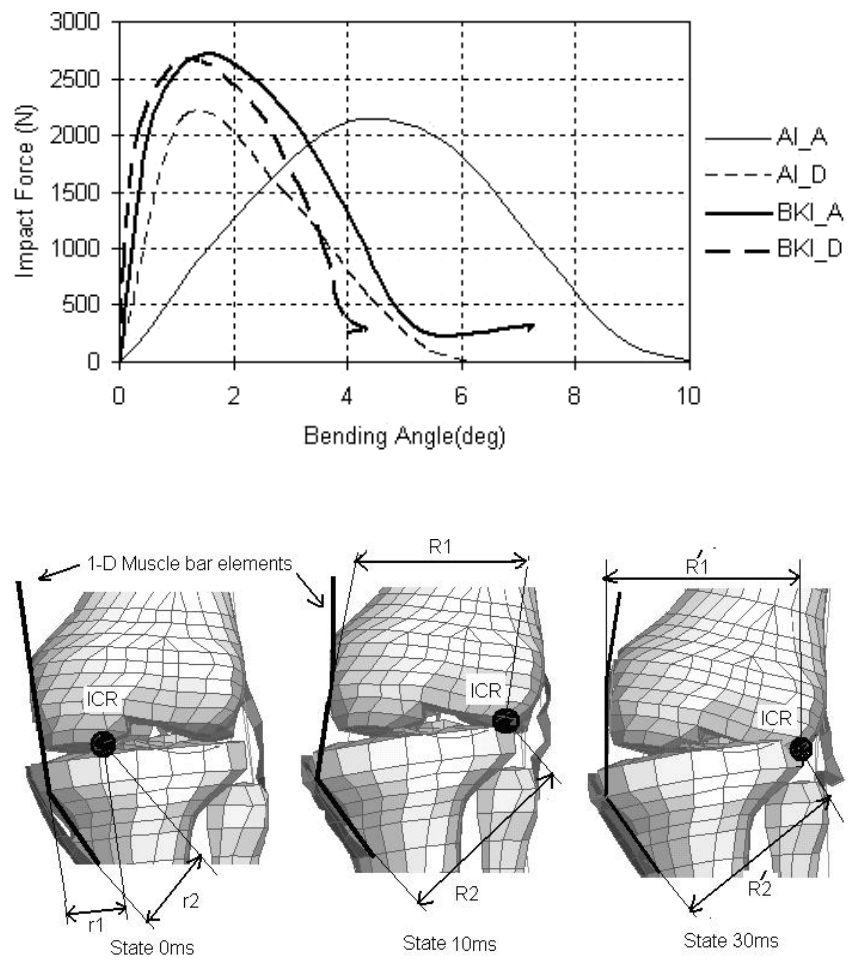

Figure 10. Comparison of impact force variation with bending angle for below-knee impact (BKI) and ankle impact (AI) with activated and deactivated muscles.

Figure 11. Change in instantaneous center of rotation and change in moment arms of muscle forces during post impact movement of the knee.

\section{Conclusion}

Experiments were conducted on muscle tissues in transverse impacts to simulate the loading during pedestrian-car impacts. The experimental results were used to identify the constitutive property of the muscle tissue when modelled as a linear visco-elastic material. The properties deduced differ from earlier reported results obtained from cadaver tests. The effect of muscle activation on probability of ligament injury was studied by modelling 40 lower limb muscles using the Hill model. Enabling muscle activation was seen to lower the loading and hence the probability of injury in ligaments.

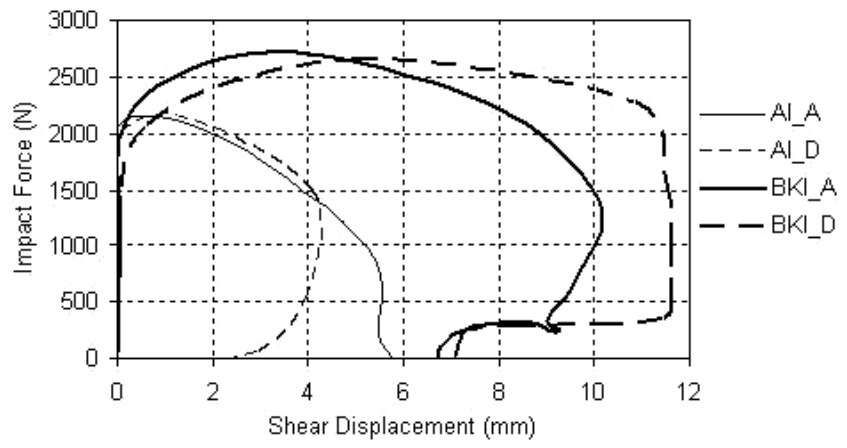

Figure 12. Comparison of impact force variation with shear displacement for below knee impact (BKI) and ankle impact (AI) with activated and deactivated muscles. 
Ideally, a method of analytically deducing the characteristics from tests data, as opposed to the current numerical procedure would have been preferred. The experimental study should be extended to strain rates up to 1000/s. It was observed that a single linear visco-elasic material law was not a good estimator over all the strain rate range. An alternate model to estimate the response over a wider range should be identified. Variations in the properties with respect to tissue region, age and other parameters could also be a subject of future study.

\section{References}

Amis A A, Firer P, Mountney J, Senavongse W, Thomas N P 2003 Review: Anatomy and biomechanics of the medial patellofemoral ligament. The Knee 10: 215-220

Arnoux P J, Kang H S, Kayvantash K 2001 The Radioss Human model for Safety. Arch. Physiol. Biochem. 109: 109-113

Audu M L 1985 The influence of muscle model complexity in musculoskeletal motion modelling. J. Biomech. Eng. 107:147-157

Azuma H, Yasuda K, Tohyama H, Sakai T, Majima T, Aoki Y, Minami A 2003 Timing of administration of transforming growth factor-beta and epidermal growth factor influences the effect on material properties of the in situ frozen-thawed anterior cruciate ligament. J. Biomech. 36: 373-381

Bandak F A, Tannous R E, Toridis T 2001 On the development of an osseo-ligamentous finite element model of the human ankle joint. Int. J. Solids Struct. 38: 1681-1697

Best T M, McElhaney J, William E G, Myres B S 1994 Characterization of the passive response of live skeletal muscle using the quasi-linear theory of visco-elasticity. J. Biomech. 27: 413-419

Bonifasi-Lista C, Lake S P, Small M S, Weiss J A 2005 Visco-elastic properties of the human medial collateral ligament under longitudinal, transverse and shear loading. J. Orthopaedic Res. 23: 67-76

Bosboom E M H, Hesselink, M K C, Oomens, C W J, Bouten, C V C, Drost, M R, Baaijens, F P T 2001 Passive transverse mechanical properties of skeletal muscle under in vivo compression, J. Biomech. 34: 1365-1368

Boyer M I, Meunier M J, Lescheid J, Burns M E, Gelberman R H, Silva M J, Louis S T 2001 The Influence of cross-sectional area on the tensile properties of flexor tendons. J. Hand Surg. 26: 828832

Brolin K, Halldin P, and Leijonhfvud I 2005 The effect of muscle activation on neck response. Traffic injury prevention. 6: 67-76

Chawla A, Mukherjee S, Mohan D, Parihar A 2004 Validation of lower extremity model in THUMS. Proceedings of IRCOBI conference, Graz, Austria, 155-166

Close R I 1972 Dynamic properties of mammalian skeletal muscles. Physiol. Rev. 52: 27-36

Crisco J J, Moore D C, McGovern R D 2002 Strain-rate sensitivity of the rabbit MCL diminishes at traumatic loading rates. J. Biomech. 35: 1379-1385

Crowe A 1970 A mechanical model of muscle and its application to the intrafusal fibres of mammalian muscle spindle. J. Biomech. 3: 583-592

Dar F H, Meakin J R, Aspden R M 2002 Statistical methods in finite element analysis, J. Biomech. 35: $1155-1161$

De Jager M K J 1996 Mathematical head-necks models for acceleration impacts. Doctors' Thesis. Technical University of Eindhoven, Eindhoven, The Netherlands

De Vita R, Slaughter W S 2005 A structural constitutive model for the strain rate-dependent behaviour of anterior cruciate ligaments. Int. J. Solids Struct. Article in press.

Delalleau A, Josse G, Lagarde J, Zahouani H, Bergheau J M 2005 Characterization of the mechanical properties of skin by inverse analysis combined with the indentation test. J. Biomech. Article in press.

Dhaliwal T S, Beillas P, Chou C C, Prasad P, Yang K H, King A I 2002 Structural response of lower leg muscles in compression: A low impact energy study employing volunteers, cadavers and the hybrid III. Stapp Car Crash Journal 46: 229-243 
Durand-Reville M, Tiller Y, Paccini A, Lefloch A, Delotte J, Bongain A, Chenot J L 2004 Immediate post-operative procedure for identification of the rheological parameters of biological soft tissue. International Congress Series 1268: 407-412

Erdemir A, Viveiros M L, Ulbrecht J S, Cavanagh P R 2005 An inverse finite-element model of heelpad indentation. J. Biomech. Article in press.

Evans 1973 Mechanical properties of bones, (Springfield, USA: Charles C Thomas Publishers)

Fleming B C and Beynnon B D 2004 In Vivo measurement of ligament/tendon strains and forces: A review. Ann. Biomed. Eng. 32: 318-328

Funk J R, Hall G W, Crandall J R, Pilkey W D 2000 Linear and Quasi-Linear Visco-elastic Characterization of ankle ligaments. J. Biomech. Eng. 122: 15-22

Gardiner 2002 Computational modelling of ligament mechanics, Ph.D. Dissertation, Bioengineering, University of Utah, Salt Lake City, USA

Glitsch U and Baumann W, 1997, The three-dimensional determination of internal loads in the lower extremity, J. Biomech. 30(11-12): 1123-1131

Gottlieb G L, and Agarwal G C 1971 Dynamic relationship between isometric muscle tension and the electromyogram in man. J. Appl. Physiol. 30: 345-351

Happee R, Hoofman M, Kroonenberg A J V, Morsink P, Wismans J 1998 A mathematical human body model for frontal and rearward seated automotive impact loading. SAE Trans. 983159: 2720-2734

Hill A V 1938 The heat of shortening and the dynamic constants of muscle. Proc. Royal Soc. 126B: 136-195

Hingorani R V, Provenzano P P, Lakes R S, Escarcega A, Vanderby Jr R 2004 Non-linear Viscoelasticity in Rabbit medial collateral ligament. Ann. Biomed. Eng. 32: 306-312

Humphrey J D 2002 Continuum biomechanics of soft biological tissues. Proc. Royal Soc. London 175: $1-44$

Iwamoto M, Kisanuki Y, Watanabe I, Furusu K, Miki K, Hasegawa J 2002 Development of a finite element model of the total human model for safety (THUMS) and application to injury reconstruction. Proceedings of IRCOBI conference, Munich, Germany, 31-42

Iwamoto M, Omur K, Kimapara H, Nakahaira Y, Tamura A, Watanabe I, Miki K 2003 Recent advances in THUMS: development of individual internal organs, brain, small female and pedestrian model. Proceedings of 4th European LS Dyna Users conference 1-10

Iwamoto M, Tamura A, Furusu K, Kato C, Miki K, Hasegawa J, Yang K H 2000 Development of a finite element model of the human lower extremity for analyses of automotive crash injuries, $S A E$ Trans. 2000-01-0621: 846-853

Kajzer J, Schroeder G, Ishikawa H, Matsui Y, Bosch U 1997 Shearing and bending effects at the knee joint at high speed lateral loading. SAE Trans. 973326: 151-165

Kajzer J, Ishikawa H, Matsui Y, Schroeder G, Bosch U 1999 Shearing and bending effects at the knee joint at low speed lateral loading. SAE Trans. 1999-01-0712: 1-12

Karthikeyan B, Mukherjee S, Chawla A 2005 Characterization of soft tissue under impact loading. Proceedings of JSAE Annual Congress, Yokohama, Japan, 47: 5-8

Karthikeyan B, Mukherjee S, Chawla A 2006 Inverse finite element characterization of soft tissues using impact experiments and Taguchi methods. SAE Wold Congress 2006, Paper No. 2006-010252

Kauer M, Vuskovic V, Dual J, Szekely G, Bajka M 2002 Inverse finite element characterization of soft tissues. Med. Image Anal. 6: 275-287

Kerrigan J R, Bhalla K S, Madeley N J, Funk J R, Bose D, Crandall J R 2003 Experiments for establishing pedestrian-impact lower limb injury criteria. SAE Trans. 2003-01-0895

Lepetit J, Faviera R, Grajalesb A, Skjervoldc P O 2004 A simple cryogenic holder for tensile testing of soft biological tissues. J. Biomech. 37: 557-562

Liao J, Vesely I 2003 A structural basis for the size-related mechanical properties of mitral valve chordae tendineae. J. Biomech. 36: 1125-1133 
Limbert G, Middleton J 2005 A constitutive model of the posterior cruciate ligament. Med. Eng. Phys. Article in press

Lizee E, Robin S, Song E, Bertholan N, Lecoz J Y, Besnault B, Lavaste F 1998 Development of 3D Finite Element Model of the human body. SAE Trans. 983152: 2760-2782

Louie J K, Kuo C Y, Gutierrez M D and Mote C D J 1984 Surface EMG measurements and torsion during snow skiing: laboratory and field tests. J. Biomech. 17: 713-724

Lynch H A, Johannessen W, Wu J P, Jawa A, Elliott D M 2003 Effect of fiber orientation and strain rate on the non-linear uniaxial tensile material properties of tendon. J. Biomech. Eng. 125: $726-731$

Maeno T, Hasegawa J 2001 Development of a finite element model of the total human model for safety (THUMS) and application to car-pedestrian impacts. Proceedings of 17th international ESV conference, Amsterdam, The Netherlands, Paper No. 494: 1-10

Maganaris C N 2002 Tensile properties of in vivo human tendinous tissue, J. Biomech. 35: 1019-1027

Matsui Y 2001 Biofidelity of TRL legform impactor and injury tolerance of human leg in lateral impact. Stapp Car Crash Journal 45: 495-510

McElhaney J, 1966 Dynamic response of bone and muscle tissue. J. Appl. Physiol. 21: 1231-1236

Miller K, Chinzei K 1997 Constitutive modelling of brain tissue: experiment and theory, J. Biomech. 30: $1115-1121$.

Miller-Young J E, Duncan N A, Baroud G, 2002 Material properties of the human calcaneal fat pad in compression: experiment and theory. J. Biomech. 35: 1523-1531

Moon D K, Woo S L-Y, Takakura Y, Gabriel M T, Abramowitch S D 2005 The effects of refreezing on the viscoelastic and tensile properties of ligaments. J. Biomech. Article in press

Moulton, M J, Creswell L L 1995 An inverse approach to determining myocardial material properties. J. Biomech. 28: 935-948

Mow V C, Ateshian G A, Spilker R L 1993 Biomechanics of diarthrodial joints: a review of twenty years of progress. J. Biomech. Eng. 115: 460-467

Mukherjee S, Chawla A, Mohan D, Metri M, 2003 Modelling of body parts consisting of bones as well as soft tissues: an experimental and finite element study. Proceedings of IRCOBI conference, Lisbon, Portugal, 567-568

Myres B S, Woolley C T, Slotter T L, Garrett W E, Best T M 1998 The influence of strain rate on the passive and stimulated engineering stress-large strain behaviour of the rabbit tibialis anterior muscle. Trans. ASME- J. Biomech. Eng. 120: 126-132

Nagasaka K, Mizuno K, Tanaka E, Yamamoto S, Iwamoto M, Miki K, Kajzer J 2003 Finite element analysis of knee injury in car-to-pedestrian impacts. Traffic Injury Prevention 4: 345-354

$\mathrm{Ng} \mathrm{H} \mathrm{W,} \mathrm{Teo} \mathrm{E} \mathrm{C,} \mathrm{Lee} \mathrm{V} \mathrm{S,} 2004$ Statistical factorial analysis on the material property sensitivity of the mechanical responses of the $\mathrm{C} 4-\mathrm{C} 6$ under compression, anterior and posterior shear. J. Biomech. 37: 771-777

Pioletti D P 1997 Visco-elastic properties of soft tissues: application to knee ligaments and tendons. Ph.D. Dissertation. Ecole Polytechnique Federale De Lausanne-Lausanne.

Pioletti D P, Rakotomanana L R 2000 Non-linear visco-elastic laws for soft biological tissues, European Journal Mechanics A/Solids 19: 749-759

Pioletti D P, Rakotomanana L R, Benvenuti J F, Leyvraz P F 1998 Visco-elastic constitutive law in large deformations: application to knee ligaments and tendons. J. Biomech. 31:753-757

Pioletti D P, Rakotomanana L R, Leyvraz P-F 1999 Strain rate effect on the mechanical behaviour of the anterior cruciate ligament-bone complex. Med. Eng. \& Phys. 21: 95-100

Pope M H, Johnson R J, Brown D W, Tighe C 1979 The role of musculature in injuries to the medial collateral ligament. J. Bone and Joint Surg. 62: 398-402

Provenzano P P, Lakes R S, Corr D T, Vanderby Jr. R 2002 Application of non-linear viscoelastic models to describe ligament behaviour. Biomechanics and Modelling in Mechanobiology, 1: $45-57$

Quapp, K M, Weiss J A 1998 Material characterization of human medial collateral ligament. Transactions of the ASME- J. Biomech. Eng. 120: 757-762 
Robinson P S, Lin T W, Reynolds P R, Derwin K A, Iozzo R V, Soslowsky L J 2004 Strain-rate sensitive mechanical properties of tendon fascicles from mice with genetically engineered alterations in collagen and decorin. Transactions of the ASME-J. Biomech. Eng. 126: 252-257

Schuster, J P, Chou C C, Prasad P, Jayaraman G 2000 Development and validation of a pedestrian lower limb non-linear 3-D finite element model. Stapp Car Crash Journal 44

Sharkey N A, Smith T S, Lundmark D C 1995 Freeze clamping musculo-tendinous junctions for in vitro simulation of joint mechanics. J. Biomech. 28: 631-635.

Song Y, Debski R E, Musahl V, Thomas M, Woo S L-Y 2004 A three-dimensional finite element model of the human anterior cruciate ligament: A computational analysis with experimental validation. J. Biomech. 37: 383-390

Soni A, Chawla A, Mukherjee S, 2006 Effect of active muscle forces on the response of knee joint at low speed lateral impacts, SAE Wold Congress 2006, Paper No. 2006-01-0460

Sverdlik A, Lanir Y 2002 Time-dependent mechanical behaviour of sheep digital tendons, including the effects of preconditioning. Trans. ASME- J. Biomech. Eng. 124: 78-84

Takahashi Y, Kikuchi Y, Mori F, Konosu A 2002 Advanced FE lower limb model for pedestrians. Proceedings of $18^{\text {th }}$ International ESV conference, Nagoya, Japan

TNO 2001 Madymo V6·0, TNO automotive, Delft, The Netherlands

Untaroiu C, Darvish K, Crandall J, Deng B, Wang J-T 2005 Characterization of the lower limb soft tissues in pedestrian finite element models. Proceedings of $19^{\text {th }}$ ESV conference, Washington DC, USA

Van D L 1998 Mechanical modelling of skeletal muscle functioning. Ph.D. Dissertation, University of Twente, Enschede, The Netherlands

Van Eijden T M G J, Turkawski S J J, Van Ruijven L J, Brugman P 2002 Passive force characteristics of an architecturally complex muscle. J. Biomech. 35: 1183-1189

Van Sligtenhorst C, Cronin D S, Brodland G W 2005 High strain rate compressive properties of bovine muscle tissue determined using a split Hopkinson bar apparatus. J. Biomech. Article in press

Viano, D C 1986. Biomechanics of bone and tissue: A review of material properties and failure characteristics. SAE Trans. 861923: 33-63

Weiss J A, Gardiner J C, Bonifasi-Lista C 2002 Ligament material behaviour in non-linear, viscoelastic and rate-independent under shear loading. J. Biomech. 35: 943-950

Weiss, J A 1994 A constitutive model and finite element representation for transversely isotropic soft tissues. Ph.D. Dissertation, Bioengineering, University of Utah, Salt Lake City, USA

Weiss J A, Maker B N, Govindjee S 1996 Finite element implementation of incompressible, transversely isotropic hyperelasticity. Comput. Methods Appl. Mech. Eng. 135: 107-128

Wieloch P, Buchmann G, Roth W, Rickert M 2004 A cryo-jaw designed for in vitro tensile testing of the healing Achilles tendons in rats. J. Biomech. 37: 1719-1722

Winters J M 1990 Hill based muscle models: a systems engineering perspective, Multiple muscle systems. Biomechanics and Movement Organization (New York: Springer-Verlag)

Winters J M, Stark L 1988 Estimated mechanical properties of synergistic muscles involoved in movements of a variety of human joints. J. Biomech. 12: 1027-1041

Woo S L-Y, Orlando C A 1986 Effects of postmortem storage by freezing on ligament tensile behaviour. J. Biomech. 19: 399-404

Wren T A L, Yerby S A, Beaupre G S, Carter D R 2001 Mechanical properties of the human Achilles tendon, Clinical Biomech. 16: 245-251

Yamada H 1970 Strength of biological materials (Baltimore: The Williams \& Wilkins Company)

Yamamoto S, Saito A, Nagasaka K, Sugimoto S, Mizuno K, Tanaka E, Kabayama M 2003 The strain-rate dependence of mechanical properties of rabbit knee ligaments, Proceedings of 18th ESV conference, Nagoya, Japan

Yin L, Elliott D M 2004 A bi-phasic and transversely isotropic mechanical model for tendon: application to mouse tail fascicles in uniaxial tension. J. Biomech. 37: 907-916 